\title{
OUSADIA CRIATIVA NAS PRÁTICAS DE EDUCADORES MATEMÁTICOS
}

\section{CREATIVE BOLDNESS IN THE PRACTICES OF MATHEMATICAL EDUCATORS}

\author{
Cidimar Andreatta \\ Universidade Cruzeiro do Sul / cidimarcol@gmail.com \\ Norma Suely Gomes Allevato \\ Universidade Cruzeiro do Sul / normallev@gmail.com
}

\begin{abstract}
Resumo
O objetivo desta resenha é apresentar uma análise crítica do livro intitulado Ousadia Criativa nas Práticas de Educadores Matemáticos, organizado pelas Professoras Doutoras Beatriz Silva D’Ambrósio e Celi Espasandin Lopes, Campinas, SP, Mercado das Letras, 2015.
\end{abstract}

\section{- Apresentando as autoras}

Beatriz Silva D'Ambrósio (em memória) possui graduação em Matemática pela Universidade Estadual de Campinas, Mestrado e Doutorado em Educação Matemática pela Indiana University, USA. Foi Professora Titular de Educação Matemática na Miami University de Ohio, USA, e Membro do Grupo de Estudos e Pesquisas em Educação Estatística e Matemática (GEPEEM), certificado pela Universidade Cruzeiro do Sul.

Celi Espasandin Lopes possui graduação em Licenciatura Plena em Matemática pela Universidade de Taubaté, graduação em Licenciatura Plena em Pedagogia pela Faculdade de Educação de Guaratinguetá, mestrado e doutorado em Educação pela Universidade Estadual de Campinas e pós-doutorado na The University of Geórgia, USA. É líder do Grupo de Estudos e Pesquisas em Educação Estatística e Matemática (GEPEEM), certificado pela Universidade Cruzeiro do Sul.

As autoras têm vasta experiência docente e de pesquisa na área de Educação Matemática, apresentando uma vasta produção envolvendo Educação Estatística, Educação Matemática na Educação Infantil e Anos Iniciais, Modelagem Matemática e Formação de Professores. É neste último tema, especialmente, que se inserem suas produções e reflexões mais recentes sob a perspectiva da "insubordinação criativa", e que se constitui o eixo da obra por nós resenhada.

\section{- Apresentando a obra}

O livro Ousadia Criativa nas Práticas de Educadores Matemáticos é composto de dez seções/capítulos, além da apresentação e posfácio, totalizando 288 páginas. Constitui-se, assim, em um conjunto de textos que desenvolvem reflexões e apresentam resultados de pesquisas desenvolvidas por diversos pesquisadores, em diversas linhas de 
pesquisa no âmbito da Educação Matemática, agrupados na obra pelo "fio condutor" dos pressupostos da insubordinação criativa nas práticas docentes.

\section{Capítulo 1: Insubordinação criativa consentida e esperada na formação de professores dos anos iniciais. Autora: Maria Auxiliadora Bueno Andrade Megid.}

O artigo de Megid apresenta discussões, reflexões e experiências de trabalho com professores e futuros professores que se reúnem para discutir suas práticas pedagógicas. O texto está organizado em quatro partes, com destaque para os seguintes aspectos.

$\mathrm{Na}$ primeira parte a autora aborda questões relacionadas ao pouco tempo que é reservado às discussões sobre a Matemática na formação de professores dos anos iniciais do Ensino Fundamental. A autora considera que os modelos de formação dos cursos de pedagogia precisam ser investigados e revisitados, uma vez que, atualmente, são esses cursos que oferecem aos seus estudantes habilitações para atuar na docência da educação infantil, nos anos iniciais do Ensino Fundamental e na gestão escolar. O que se tem assistido é uma formação pretensamente ampla, porém, muito superficial e particular em relação ao ensino de Matemática e a outras áreas específicas do conhecimento.

$\mathrm{Na}$ segunda parte do artigo, são apresentadas discussões acerca de atividades realizadas com professoras em aulas de Matemática do curso de Pedagogia, consideradas, por elas, como insubordinação consentida. O trabalho realizado culminou com a descrição de narrativas que revelam aspectos e experiências negativas das professoras em relação ao ensino da Matemática no curso de Pedagogia.

$\mathrm{Na}$ terceira parte, a autora apresenta outra abordagem para insubordinação, denominada por ela de insubordinação continuada, por meio de uma experiência que desenvolveu com duas professoras egressas do curso de Pedagogia em relação ao ensino da disciplina de Matemática que vivenciaram na graduação em Pedagogia. Uma das professoras era mais experiente, ou seja, tinha mais tempo de serviço no magistério antes mesmo de ingressar no curso de Pedagogia. Por isso, ela considera que o curso se constituiu em um contexto de formação continuada, pois pôde fazer associações e alterações nas aulas de Matemática que ministrava a partir do que aprendia na disciplina de Matemática oferecida nessa graduação. A outra professora não tinha experiência docente antes de ingressar no curso de Pedagogia, sendo aprovada em concurso público do magistério logo após a graduação. Essa professora relata que se sentia muito sozinha na escola em que atuava e que recebia pressão dos gestores, o que acabava fragilizando seu trabalho. Vale ressaltar que essa professora não desistiu e manteve seu "espírito de investigação", pois sabia da importância do seu trabalho para a aprendizagem dos estudantes.

$\mathrm{Na}$ última parte do texto, Megid expõe o trabalho que realiza com um grupo de estudos sobre o ensino de Matemática, constituído por professoras da Educação Infantil e anos iniciais do Ensino Fundamental e estudantes do curso de Pedagogia, cujo trabalho apóia-se em quatro elementos fundamentais: o foco no ensino e na aprendizagem da Matemática, a organização do grupo colaborativo, a discussão das práticas pedagógicas e a escrita de narrativas. Os estudos do grupo são permeados pelas narrativas e, a partir 
dai, são realizadas as discussões, de modo que o trabalho de cada um é ressignificado a partir das concepções de cada professor.

A autora finaliza motivando os leitores a organizarem grupos de estudos em escolas, de preferência com a anuência das pessoas, para estudos e reflexões sobre a prática docente, sempre buscando a insubordinação criativa, e tomando-se os cuidados necessários para que as pressões diárias sobre o profissional não desestabilizem seus desejos de ensinar de forma inovadora e planejada.

As questões discutidas por Megid nos fazem refletir sobre a importância que estamos dando às disciplinas de conteúdos e metodologias do ensino de Matemática nos cursos de Pedagogia, de forma que tenhamos mais práticas que abordem tanto os conceitos matemáticos como os procedimentos para o seu ensino, as dúvidas, as diferentes formas de ensino e de resolução de problemas, as práticas observadas nos estágios, bem como as possibilidades de superação das dificuldades e problemas encontrados.

Neste sentido, depreende-se do artigo de Megid a necessidade de incentivarmos ações que promovam manifestações criativas no interior das escolas; que incentivemos novas práticas docentes que extrapolem as repetições e práticas engessadas; que ocorra o diálogo e reflexões acerca do trabalho pedagógico para, assim, aprender em conjunto com os colegas e estabelecer novas relações no processo de ensino e aprendizagem.

\section{Capítulo 2: Aprendizagem, a prática docente e alguns indícios de insubordinação criativa de professoras que ensinam Matemática na infância.}

O referido capítulo apresenta alguns pontos discutidos nas pesquisas de doutorado de Antonio Carlos de Souza e Débora de Oliveira, defendidas em 2013 no Programa de Pós-Graduação em Ensino de Ciências e Matemática da Universidade Cruzeiro do Sul.

A pesquisa de Souza foi realizada com um grupo formado por seis professoras que lecionam na Educação Infantil e uma no primeiro ano do Ensino Fundamental. Souza investigou quais contribuições um processo de aprendizagem docente centrado na reflexão pode trazer para a inclusão da Estocástica na Infância. O trabalho de Oliveira contou com a participação de um grupo de treze professoras que lecionam na Educação Infantil e nos Anos Iniciais do Ensino Fundamental, e buscou investigar aprendizagens reveladas por professores que ensinam Matemática para crianças com foco em Estocástica. Os autores apóiam-se na definição de Estocástica presente nos estudos de Celi Espasandin Lopes, como sendo a interface entre os conceitos de Combinatória, Probabilidade e Estatística, envolvendo formas de pensamentos particulares.

No capítulo em questão, os autores apresentam recortes da participação de duas professoras nos grupos de estudos das pesquisas que realizaram, cujo objetivo era a elaboração e a aplicação de atividades que contivessem idéias relacionadas à Estocástica, buscando verificar indícios de insubordinação criativa em suas práticas.

As professoras foram identificadas pelas letras "T" e "E". A professora "T", na ocasião da pesquisa, tinha 17 anos de profissão docente e lecionava para uma turma composta de 18 alunos de primeiro ano do Ensino Fundamental. A professora "E" tinha 13 
anos de profissão docente e lecionava para uma turma de Berçário I e II, com idades entre 1 ano e 3 anos.

A professora "T" considera que é um grande problema ensinar Matemática sem estabelecer um vínculo com a vida real, e que a idade dos alunos não deve ser justificativa para se construírem "rótulos" e impedimentos para o ensino de determinados conteúdos matemáticos. Considera, assim, importante e possível abordar ideias estatísticas na Educação Infantil, pois entende que a Estatística pode ajudar na compreensão da Matemática, demonstrando que o ensino de Estatística vai muito além de construir gráficos.

A professora "E", participante da pesquisa de Oliveira, demonstrou uma preocupação em desenvolver o domínio necessário para a construção do conhecimento matemático na infância. O trabalho realizado pela professora apresentou indícios de insubordinação criativa quando desenvolveu uma atividade com seus alunos do Berçário II por meio da adivinhação de personagens, em uma atividade denominada Senha/Segredo. A professora precisou alterar o jogo usando apenas dois personagens infantis, quando observou que a quantidade de personagens estava trazendo dificuldades na realização das atividades pelas crianças.

As ações das Professoras T e E, foram consideradas como atitudes ousadas e promoveram nos estudantes uma aprendizagem do conhecimento matemático com significado, assim como demonstraram a possibilidade de os docentes criarem alternativas para o ensino da Matemática, usar a criatividade no fazer pedagógico, além de evidenciarem a necessidade de os professores assumirem que não se sabe tudo, mas que devem estar sempre em processo de formação para, assim, construírem novos saberes, fazeres, ideias e valores.

\section{Capítulo 3: Professores de Matemática em formação: invenções e (sub)versões}

O capítulo 3, de autoria de Sonia Maria Clareto e Giovani Cammarota, apresenta discussões sobre diferentes versões da prática docente, intituladas: (1) (sub)versão da prática docente na formação; (2) Uma versão - professores em formação em um curso de licenciatura em Matemática em uma universidade pública brasileira; e (3) Uma (sub)versão - movimento de invenção de vida e de Matemática e de si e de mundos em aprendizagens, Vida e Existência.

Todas essas versões provocam questionamentos acerca dos processos de formação inicial de professores de Matemática. Os questionamentos referem-se ao que realmente acontece nas "entrelinhas" da formação de um professor de Matemática. As autoras apresentam um conjunto de disciplinas que fazem parte dessa formação e que provocam esses questionamentos em torno de desconstruir, desmanchar, construir, inventar, ou seja, indo de encontro ao que está posto como habitual e considerando como conjunto de regras na formação dos professores.

Pensar numa (sub)versão dessa formação significa pensar numa versão menor da formação de professores num curso de licenciatura em Matemática. Significa pensar processos diferentes e inventivos de formação. Clareto e Cammarota destacam a (in)disciplina Saberes Matemáticos Escolares, ministrada em um Curso de Licenciatura 
que analisaram e que, de certa forma, tem a proposição de fazer esse movimento inventivo da formação de professores de Matemática. A disciplina é constituída por "exercícios de pensamento" que têm a missão de romper com um pensamento habitual e colocar outras formas de pensamento em exercício, em movimento, fazendo uma relação com uma Matemática Menor ${ }^{1}$ do pensamento. É importante destacar que a Matemática Menor não tem a intenção de tornar-se uma Matemática Maior; pelo contrário, a Matemática Menor guarda suas singularidades e regime de funcionamento próprio e modos de pensar a Matemática diferente do habitual.

Clareto e Cammarota apresentam diferentes versões para o pensamento matemático utilizando exemplos de adição, multiplicação e divisão de frações, fazendo relação entre a forma habitual de resolução por algoritmos e a forma diferente, chamada por eles de perturbação do pensamento, sendo uma forma diferente de aprender a pensar matematicamente. Essa forma diferente envolve uma opção ética do professor comprometido com uma formação discente significativa, considerada como uma sub(versão) e, porque não dizer, uma insubordinação.

\section{Capítulo 4: Algumas insubordinações criativas presentes na prática de uma professora de Matemática}

O quarto capítulo, produzido por Gabriela Felix Brião, relata algumas experiências de insubordinação criativa de uma professora de Matemática de um Colégio de Aplicação, em cujos processos estão envolvidos alunos, professores, conteúdos e estagiário - futuro professor.

Inicialmente, Brião apresenta reflexões em relação a: o que realmente a Matemática é? Que tipo de Ciência? Quais são seus objetos de estudos? Quais são suas ferramentas?

A partir dessas reflexões, a autora ressalta que, não raro, a normalidade em uma sala de aula de Matemática, nos dias de hoje, significa transmitir definições, regras, procedimentos e axiomas. Será considerado insubordinado, dentro do espaço escolar, todo ato movido pela intuição do insubordinado que se indisponha contra o sistema instituído, sob a bandeira de promover uma aprendizagem efetiva dos envolvidos (professores e alunos).

Considerando os três elementos (alunos, professores e estagiário - futuro professor) envolvidos no contexto de sala de aula, a relação de insubordinação ocorre, para o aluno, por exemplo, quando este consegue trazer diversas soluções para um mesmo problema proposto, quando questiona o movimento do professor e apresenta soluções alternativas.

Para o professor, a insubordinação criativa ocorre quando proporciona um movimento de libertação de ideias dos alunos (problematizador), ao assumir que os alunos precisam sentir-se à vontade para exporem seus pensamentos e, aos poucos, irem adquirindo autonomia para lidar e refletir com questões mais complexas.

\footnotetext{
1 As autoras destacam que essa Matemática "Menor" refere-se a um modo diferente de pensar a Matemática tendo em vista os modos "majoritários" e "fixos" de pensar a Matemática, associada nesse caso a uma Matemática "Maior".
} 
A insubordinação criativa do estagiário (futuro professor) ocorre quando, ao auxiliar o professor e estudantes, é rechaçado pela escola, e ao combater essa força a favor do ensino. Brião considera que um olhar para uma sala de aula "insubordinada" de Matemática pode mostrar um ambiente onde ideias florescem e onde a liberdade de ser é valorizada. Nesse sentido, a autora defende que fazer Matemática exige trabalho colaborativo entre professor e aluno, e que desenvolver problemas investigativos em sala de aula evidencia uma nova dimensão, incomum às vivências escolares dos professores, levando a situações de insubordinação.

Na parte final do capítulo, Brião apresenta relatos de uma prática insubordinada em um Colégio de Aplicação da Universidade em que atua, destacando que as turmas são divididas em grupos de afinidades, que há uma maneira muito espontânea de lidar com a Matemática e muita naturalidade de lidar com os problemas em sala de aula. Destaca que a pressão do sistema é demasiada e quase a totalidade dos professores utiliza os métodos tradicionais de ensino.

O objetivo das reflexões que desenvolve no texto é mostrar às pessoas em formação que o trabalho em conjunto pode ser benéfico para a resolução de problemas, seja de que ordem for. E, ademais que é necessário que fujamos do que é imposto, e dos obstáculos e entraves burocráticos que surgem na escola; que sejamos pessoas mais ousadas, embora sempre respeitando as opiniões alheias e valorizando o trabalho colaborativo entre professor e aluno.

\section{Capítulo 5: Nós nos constituímos naturalmente insubordinados e, assim, nosso trabalho também...}

O capítulo em questão, escrito por Conceição Aparecida da Cruz Longo, apresenta relatos de sua experiência docente que a constitui como "naturalmente insubordinada", conclusão a que chegou após refletir e reviver alguns episódios de sua carreira docente.

O texto de Longo está dividido em quatro episódios, intitulados respectivamente de: Episódio 1: O caso do livro didático; Episódio 2: O caso da modelagem matemática; Episódio 3: O caso do teorema das quatro cores; e Episódio 4: O caso da calculadora.

No episódio (1), Longo apresenta relatos da experiência que vivenciou quando se efetivou como professora na rede estadual de ensino de São Paulo, em 2006. Destaca que se sentiu muito angustiada quando a diretora da escola apresentou a coleção de livros didáticos do professor, pois a proposta metodológica presente nos livros era muito contrária à sua metodologia de ensino. Longo queria muito trabalhar com outros livros, pois queria mostrar o seu talento como professora, fazendo com que a teoria e a prática caminhassem juntas. Relata que, aos poucos, conseguiu com que os pais comprassem o livro indicado por ela, caracterizando essa prática como naturalmente insubordinada e criativa.

O episódio (2) está relacionado à experiência com uma turma de $9^{\circ}$ ano da Educação de Jovens e Adultos na rede municipal de São Paulo, também no ano letivo de 2006. A preocupação da autora estava voltada à dificuldade dos alunos em contextualizar os conteúdos sistematizados na escola com sua vivência fora dela. Nesse sentido, Longo procurou minimizar essas dificuldades propondo atividades que rompessem com o papel 
tradicional de uma aula de Matemática, trabalhando a partir de situações reais dos estudantes para, posteriormente, serem problematizadas.

O episódio (3), intitulado o caso do teorema das quatro cores, está relacionado ao trabalho com Topologia. O desejo de trabalhar com essa temática surgiu no Grupo de Estudos do qual Longo participa, coordenado pelo Prof. Dr. Sergio Lorenzato. Longo destaca no texto que sofreu resistência por parte da direção da escola em trabalhar com essa temática, sendo questionada pelo diretor escolar em relação aos temas que estavam previstos no Plano de Curso Anual da disciplina. Ela resistiu às pressões, e conseguiu demonstrar a importância de fazer com que o aluno saiba da existência das noções intuitivas de Topologia, que, futuramente, poderão auxiliar em estudos aprofundados das Geometrias.

O quarto e último episódio relata a experiência de trabalho desenvolvida com o uso da calculadora, cujo objetivo foi mostrar, na prática, o uso da calculadora como um recurso tecnológico capaz de auxiliar os alunos a construir conhecimentos e não apenas como uma máquina de somar e subtrair. Destaca que, inicialmente, houve resistências por parte da direção escolar e dos pais quanto ao uso da mesma em suas aulas; mas, após escrever uma carta aos pais e à direção explicando os benefícios de uso da calculadora nas aulas, seu uso foi prontamente aceito.

A autora encerra o último episódio refletindo sobre o desinteresse dos alunos nas aulas, considerando que esse problema é ocasionado, em grande parte, pelo professor, que não se prepara adequada e cuidadosamente para as aulas e que utiliza metodologias defasadas.

O capítulo nos leva a refletir sobre a importância de oportunizarmos uma aprendizagem de diferentes maneiras aos alunos, de adequarmos o currículo quando necessário e de nos constituirmos naturalmente insubordinados em favor dos alunos, abrindo possibilidades de interação e diálogo entre todos os membros da comunidade escolar, de forma que todos consigam cumprir com a verdadeira tarefa de educar.

\section{Capítulo 6: Prática colaborativa de uma professora na mediação entre a leitura e a escrita em aulas de Matemática e a insubordinação criativa}

O objetivo do capítulo é apresentar a prática da professora Cidinéia da Costa Luvison, refletida e investigada em colaboração com a professora formadora Regina Célia Grando, ambas autoras do texto.

As autoras discutem, inicialmente, a complexidade da cultura escolar, com seus ritmos, normas e regras, bem como os desafios cotidianos para se criar uma cultura de aula de Matemática baseada no diálogo, na problematização, na negociação de significados e nas práticas de leitura e escrita e de colaboração. Em seguida, abordam o protagonismo docente e as relações éticas no fazer docente.

Em relação à complexidade da cultura escolar, Luvison e Grando destacam que são muitos os ritos existentes na escola que muitas vezes impedem um trabalho que rompa com o paradigma do exercício, de forma que tenhamos uma cultura diferente de aula de Matemática. A discussão desse tópico resgata a necessidade urgente de 
mudança dessa cultura e de resgate do papel do professor como peça fundamental na criação de um ambiente de aula propício a uma aprendizagem significativa em Matemática.

No tópico protagonismo docente, as discussões voltam-se à autonomia do professor em proporcionar um ambiente de sala de aula que requer um refúgio, um distanciamento dos discursos internos ao ambiente escolar, com o objetivo de observar outras propostas de ensino e novos ambientes de aprendizagem. As narrativas de Luvison, registradas no diário de aprendizagem, evidenciam esse protagonismo docente junto com os alunos em prol de aprendizagens mais significativas.

O tópico seguinte apresenta registros de aprendizagens em um ambiente colaborativo de negociação, mediadas pela escrita e pela leitura. Luvison apresenta 0 trabalho que vem sendo realizado com o significado de ler e escrever para as crianças nas aulas de Matemática, que vai além de resolver um problema ou realizar um cálculo. Nesse sentido, a autora considera importante que o aluno reflita sobre as próprias palavras, sendo autor de seu próprio texto, e que saiba posicionar-se como um escritor que se volta para o papel e escreve novamente, ressignificando sua aprendizagem. 0 trabalho desenvolvido por Luvison, no qual as crianças narram suas histórias de aulas em um ambiente colaborativo, representa espaços de insubordinação criativa, pois os alunos se sentem autores de sua aprendizagem, numa perspectiva crítica, política e ética de aprendizagem. Esse ato de liberdade propiciado aos alunos rompe com os paradigmas atuais sobre o ensino mecanizado. Desse modo, houve uma insubordinação criativa, pois possibilitou aos alunos tornarem-se mais críticos perante a sociedade.

\section{Capítulo 7: Insubordinação criativa e tecnologia informática: experiências de ensino e de formação de professores que ensinam Matemática}

As autoras Carmem Lúcia Bracaglion Passos e Ana Paula Gestoso de Souza apresentam, neste capítulo, experiências marcantes da primeira autora como formadora de professores que ensinam Matemática nos anos iniciais do Ensino Fundamental.

Passos considera o ensino de Matemática como oportunidade para a criação de "argumentações alternativas" que levem a aprendizagens mais significativas dos alunos, concebendo-o, assim, como uma forma de insubordinação criativa. No texto, ela apresenta experiências de trabalho com informática para ensinar Matemática a alunos de 6a ano, que também considera como práticas de insubordinação. O trabalho desenvolvido foi em relação às propriedades de polígonos, simetria, construção, decomposição e composição de figuras e construção de mosaicos, por meio de exploração de um software computacional.

As pesquisas apresentadas e discutidas pelas autoras no capítulo evidenciam que são poucos os professores de Matemática e licenciandos de Pedagogia que utilizam a informática em suas aulas. Dai a necessidade de questionar qual a importância de integrar ensino, aprendizagem e tecnologia. O computador é apontado pelas autoras como um recurso tecnológico e didático, a partir do momento em que a sociedade passou a utilizá-lo cada vez mais. É um instrumento que pode trazer várias possibilidades ao processo de ensino e aprendizagem da Matemática, como se pode perceber nos diversos 
programas (Prolnfo, UCA, PROUCA) disponibilizados e/ou oferecidos pelo governo com a finalidade de promover a tecnologia como ferramenta de enriquecimento pedagógico.

Passos e Souza apresentam, também, relatos de uma pesquisa de PósDoutoramento em que foram realizadas atividades de extensão, com estudantes das licenciaturas da Universidade Federal de São Carlos e professores da rede municipal de São Carlos/SP, cujo objetivo foi analisar as produções e saberes curriculares relativos à Matemática por meio da utilização de recursos tecnológicos. O objetivo era desenvolver discussões e análises da utilização de jogos eletrônicos para ensinar e aprender "Matemáticas Criativas", consideradas práticas insubordinadas, pois fugiram da estrutura curricular de um curso "padrão" de formação de professores.

Os depoimentos dos professores, apresentados no texto de Passos e Souza, evidenciam tal necessidade de interação e mediação do professor no desenvolvimento de atividades, principalmente quando envolvem recursos tecnológicos.

Finalizando o capítulo as autoras revelam que houve mudanças nas percepções dos envolvidos no curso de extensão; perceberam que as concepções de jogos mudaram, e que os professores ou futuros professores envolvidos passaram a conhecer melhor e considerar as potencialidades da utilização de jogos para ensinar Matemática. E que a forma como os docentes apresentam e interagem com os jogos e com os alunos é de extrema importância para o sucesso no ensino e na aprendizagem.

É importante destacar, ainda, que essa última experiência apontada pelas autoras configura práticas insubordinadas, também porque ajudou os participantes a sentirem-se no papel de professores protagonistas, na perspectiva de superar lacunas existentes na sua formação.

\section{Capítulo 8: Insubordinações criativas em práticas pedagógicas em Modelagem Matemática}

O capítulo de autoria de Andreia Maria Pereira de Oliveira e Jonei Cerqueira Barbosa está estruturado em quatro seções voltadas para práticas com Modelagem Matemática relacionadas à inserção de situações-problema externos à Matemática nas práticas pedagógicas.

O capítulo pretende relacionar a noção teórica de tensões nos discursos com o conceito de insubordinação criativa, a fim de analisar ações que são requeridas na inserção de Modelagem Matemática nas práticas pedagógicas.

A primeira seção discute a prática pedagógica em Modelagem e a noção teórica de tensões nos discursos; a segunda apresenta práticas pedagógicas em Modelagem de três professores; a terceira menciona a relação entre os conceitos de tensões nos discursos e insubordinação criativa; e a quarta propõe a discussão dos dados com o referencial teórico, apontando implicações para a pesquisa e a prática em Modelagem Matemática.

Os autores destacam ações específicas nas práticas pedagógicas, quando tensões foram constituídas nos discursos dos professores em diferentes momentos na condução das aulas: planejar o sequenciamento da aula, imprimindo uma nova organização; engajar os estudantes, requerendo uma participação mais ativa; discutir e intervir diante das 
respostas dos estudantes, mobilizando novos modos de trabalhar com as soluções; decidir como abordar o conteúdo matemático, requerendo outra possibilidade de trabalhar o conteúdo a partir do ambiente de Modelagem.

Na seção sobre práticas pedagógicas em Modelagem Matemática, três professores destacam que fizeram modelagem pela primeira vez num programa de formação continuada. Foram abordados os temas: Cesta Básica, Análise do consumo de água, Salário mínimo e Custo de vida de uma família na cidade de Conceição do Jacuípe-Bahia.

A seção tensões nos discursos, insubordinação criativa e práticas pedagógicas em Modelagem Matemática apresenta a tensão emergente do sequenciamento e do ritmo da prática pedagógica em Modelagem Matemática, manifestada por meio dos questionamentos: o que perguntar aos alunos; como conduzir as atividades; como controlar o tempo.

Infere-se do capítulo de Oliveira e Barbosa, que a Modelagem Matemática provoca tensões nos discursos que estão relacionadas com os princípios de comunicação e da produção de textos na prática pedagógica, bem como ações de insubordinação criativa, pois promovem alterações no quê falar e no modo de falar - rompendo com regras já constituídas na prática pedagógica. Em particular, a prática da Modelagem rompe com as formas de abordar a Matemática nas aulas, ao promover variações nos princípios comunicativos das práticas pedagógicas.

$\mathrm{Na}$ experiência de formação continuada discutida pelos autores, houve insubordinação criativa na relação entre professores e estudantes tendo em vista o ambiente da modelagem, pois instigou professores e alunos a romperem com as regras já estabelecidas em sala de aula. Observou-se o potencial da insubordinação criativa do ambiente de modelagem, uma vez que professores e estudantes romperam com as regras de produção de textos já presentes e consolidadas historicamente nas práticas pedagógicas.

\section{Capítulo 9: Cyberformação com professores de Matemática: desvelando práticas de formação/ação que podem vir ao encontro da insubordinação criativa.}

Mauricio Rosa apresenta recortes de sua pesquisa de doutorado realizada com licenciandos em Matemática, por meio de um curso online à distância que tomou o RPG como ambiente educacional de aprendizagem do conceito de 'integral definida' da disciplina de Cálculo Diferencial e Integral.

A pesquisa de Rosa, baseada numa concepção denominada de Cyberformação, assemelha-se à concepção de insubordinação criativa no sentido de que rompeu com visões educacionais impostas ou que, às vezes, não são refletidas em um curso de formação de professores, cujo "colorido" é dado pelas tecnologias digitais a fim de quebrar paradigmas que norteiam a educação como um tudo.

Rosa ressalta, em seu texto, que a concepção de Cyberformação, em geral, não é contemplada naturalmente quando se fala em uso das tecnologias na educação nos contextos de formação de professores. 
O autor apresenta três dimensões para a Cyberformação: matemática; pedagógica e tecnológica. A dimensão matemática abrange ideias, conceitos, definições e relações que se processam na formação específica de Matemática, entendida como produção do conhecimento matemático, no sentido de entender que a prática do professor de Matemática precisa desenvolver-se num contexto educativo com formas alternativas e acessíveis ao aluno nos diversos estágios escolares. Na dimensão pedagógica da Cyberformação, os processos educativos se consolidam por meio da Resolução de Problemas, Modelagem Matemática, Etnomatemática, dentre outras, em torno do design de atividades, ambientes e recursos tecnológicos.

Finalmente a dimensão tecnológica está relacionada a características de ambientes virtuais de aprendizagem, como transformação, imersão e agency. A transformação é evidenciada no tempo/espaço do mundo tecnológico, como, por exemplo, "on" e "offline". A ação se dá nas vivências online nos espaços de formação de professores com as tecnologias. A imersão está relacionada ao pensar com as tecnologias em um mundo em que estamos imersos em tecnologias, e onde manifestamos nossos desejos, sentimentos e valores, assim como os modos de pensar. O professor precisa estar imerso na tecnologia, fazer parte dela e estar "plugado", ou seja, conceber o uso das tecnologias em termos de Educação Matemática. A terceira característica denominada de agency está relacionada ao "saber-fazer-com-tecnologia", que é o ato de agir com as tecnologias no ensino de Matemática, sendo necessárias ações que relacionem a dimensão tecnológica à específica (matemática) e à pedagógica, de forma que o professor em Cyberformação aprenda a construir ações em sua própria prática docente.

Mauricio Rosa, na parte final do seu capítulo, apresenta várias experiências com diversos cursos online semipresenciais e a distância, realizados com professores e relacionados a movimentos de Cyberformação, evidenciando práticas formativas com professores de Matemática que vão ao encontro da insubordinação criativa. Tais práticas são consideradas insubordinadas, pois utilizam as ferramentas tecnológicas não mais como suporte ao ensino e aprendizagem da Matemática, mas como elementos que pertencem a uma cultura digital condicionada a práticas educativas diversificadas. Tais práticas geram experiências que transformam a Matemática em termos de produção do conhecimento, levando em consideração as dimensões específica (matemática), pedagógica e tecnológica.

\section{Capítulo 10: Insubordinações criativas relacionadas com a ação pedagógica do programa Etnomatemática}

O último capítulo do livro organizado pelas professoras Celi Espasandin Lopes e Beatriz Silva D'Ambrósio é de autoria de Daniel Clark Orey. Apresenta discussões e reflexões em relação à insubordinação criativa da ação pedagógica do Programa Etnomatemática, baseadas em três categorias: temas contextualizados no cotidiano, as representações antiprimitivistas e a tradução, a modelagem e o dinamismo cultural. Orey destaca que a Etnomatemática é um programa que investiga as maneiras pelas quais os grupos culturais compreendem, articulam e utilizam as ideias, as noções, os procedimentos e os conceitos, que podem ser identificadas como práticas matemáticas para a elaboração de atividades matemática curriculares. 
Nesse programa, os professores são considerados insubordinados quando flexibilizam as práticas pedagógicas institucionalizadas, por meio da contextualização das atividades cotidianas, tendo em vista o contexto cultural de inserção dos alunos, de forma que tenham acesso ao conhecimento matemático acadêmico. Essa perspectiva de insubordinação relaciona-se com a primeira categoria apresentada por Orey, que se refere a temas contextualizados no cotidiano. Outra perspectiva de insubordinação criativa, destacada por Orey nessa categoria, se mostra quando os professores escolhem uma determinada ação pedagógica que tem como objetivo principal o atendimento das necessidades educacionais dos alunos, indo de encontro à manutenção do status quo social, e impossibilitando o desenvolvimento da criatividade dos alunos.

A categoria representações antiprimitivistas exige que as atividades matemáticas curriculares propostas em sala de aula para o ensino de Matemática não se restrinjam ao ensino de figuras geométricas simples, por exemplo. A utilização de práticas matemáticas sofisticadas desenvolvidas por grupos culturais distintos desafia o ensino de Matemática, pois representações primitivistas são consideradas como estereótipos prejudiciais aos membros dos grupos.

A categoria tradução, modelagem e dinamismo cultural nos chama a atenção para o fato de que as culturas são dinâmicas, uma vez que suas características podem ser alteradas modificando o seu conteúdo original. Nesse sentido, o conteúdo matemático é dinâmico e também pode modificar-se, alterar-se e transformar-se com os encontros e relações sociais entre os membros de grupos culturais distintos. Um bom exemplo apresentado por Orey nesta perspectiva refere-se a uma pesquisa realizada em uma comunidade de horticultores, com investigação de ideias matemáticas presentes nas atividades de produção e comercialização de hortaliças.

Percebe-se com o texto de Orey que podemos abandonar as práticas matemáticas consolidadas, ou seja, precisamos proporcionar aos alunos uma ação pedagógica que conecte as práticas matemáticas utilizadas no cotidiano com aquelas desenvolvidas na escola/academia, combatendo uma visão primitivista. É importante que os alunos consigam estabelecer conexões entre a Matemática do senso comum/cotidiana e a Matemática acadêmica.

O autor considera importante, ainda, destacar que precisamos romper com o determinismo consolidado de que a aprendizagem matemática é determinada pela genética e não pelas relações que se estabelecem entre os diferentes grupos culturais distintos. É fundamental considerar a conexão do desenvolvimento dos alunos com o contexto social, cultural, político, econômico e ambiental nos quais estão inseridos.

\section{Posfácio: Práticas que redimensionam o sucesso da Matemática}

As autoras do livro, Lopes e D'Ambrósio, nos fazem provocações e reflexões acerca do que realmente constitui o fazer matemático, da aprendizagem e do sucesso em Matemática, defendendo práticas de forma que os alunos sejam capazes de avaliar e redimensionar o próprio conhecimento e de discutir a legitimidade de suas produções matemáticas. 
Dessas provocações, inferimos que precisamos romper de forma definitiva com o ensino por meio de regras e padrões, e buscar novos procedimentos matemáticos, didáticos e de avaliação que rompam com as classificações numéricas que fazemos com os estudantes, taxando-os como bons ou ruins em Matemática.

O livro Ousadia Criativa nas Práticas de Educadores Matemáticos traz capítulos com experiências de diversos autores sobre suas práticas insubordinadas criativamente, práticas que ocorreram em prol da aprendizagem em Matemática e que, muitas vezes, permitiram que $o$ aluno também fosse insubordinado no processo. As autoras defendem que o aprendizado deveria ser direcionado para estimular o raciocínio, a reflexão e o julgamento, evidenciando posturas críticas na identificação e resolução de problemas, buscando sempre meios de tornar os alunos cidadãos mais criativos e responsáveis na resolução de problemas da sociedade

Cada autor dos capítulos trouxe uma experiência distinta de insubordinação. Alguns considerando a própria prática com seus alunos, outros experienciando métodos e programas específicos que não estão nos currículos oficiais ou em outros documentos. São métodos, práticas e programas insubordinados que muitos professores da atualidade já conhecem, porém não aceitam, não discutem e, assim, não incorporam à sua prática profissional. Por outro lado, diante da leitura do livro, percebemos que em muitos momentos da nossa prática como professores, somos insubordinados criativamente, porém, o desconhecimento desse movimento de inércia isola o professor e o deixa mergulhado num sistema educacional caracterizado por "burocracias pedagógicas".

Fazendo uma apreciação geral do livro, destacamos que a preocupação dos diversos autores dos capítulos em suas pesquisas é a de apresentar ações insubordinadas em práticas pedagógicas na Educação Matemática, como possibilidades de ressignificar o ensino de Matemática e, assim, contribuir com a melhoria na aprendizagem dos alunos, de forma que sejam respeitados e valorizados enquanto sujeitos ativos em seu processo de escolarização.

Finalizamos a presente resenha destacando que a leitura do livro é de extrema relevância a pesquisadores, professores, estudantes de Licenciaturas em Matemática e em Pedagogia e outros profissionais da Educação que se interessam e/ou estejam envolvidos com o ensino, especialmente o de Matemática, mas também de outras áreas. $\mathrm{E}$, ainda, aos pesquisadores em Educação Matemática, cujos trabalhos buscam incessantemente romper barreiras e transcender limites, com vistas a uma aprendizagem mais efetiva e humanizada da Matemática.

\section{Referências}

D’AMBRÓSIO, Beatriz Silva. LOPES, Celi Espasandin. Ousadia Criativa nas Práticas

de Educadores Matemáticos. (Org.). Campinas, SP: Mercado das Letras, 2015.

Submissão: 22/08/2017

Aceite: $22 / 11 / 2017$ 